\title{
Immediate postpartum IUD: analysis of factors making it contraceptive of choice
}

\author{
Anshuli Trivedi ${ }^{*}$, P. K. Kasar ${ }^{2}$, Rajesh Tiwari' ${ }^{2}$, Arvind Sharma ${ }^{2}$ \\ ${ }^{1}$ Department of Community Medicine, Gandhi Medical College, Bhopal, M.P., India \\ ${ }^{2}$ Department of Community Medicine, NSCB Medical College, Jabalpur, M.P., India
}

Received: 15 September 2014

Accepted: 10 October 2014

\section{*Correspondence:}

Dr. Anshuli Trivedi,

E-mail: dranshulitrivedi@yahoo.com

Copyright: $\odot$ the author(s), publisher and licensee Medip Academy. This is an open-access article distributed under the terms of the Creative Commons Attribution Non-Commercial License, which permits unrestricted non-commercial use, distribution, and reproduction in any medium, provided the original work is properly cited.

\begin{abstract}
Background: Intrauterine devices are convenient, long term, reversible means of contraceptive. They are user friendly due to one-time application, ease of removal and immediate return of fertility on its removal. The Immediate Postpartum IUD is inserted in women within 48 hours, after normal delivery. The study aims to understand factors responsible for making IUD as the contraceptive of choice. It also identifies various social, demographic factors responsible for making IUD as the contraceptive of choice.

Methods: A cross-sectional observational study was done using pretested questionnaire. In total 470 subjects were interviewed. The data were collected and compiled using MS-excel and analyzed by using Epi info-7. Data is presented in terms of proportions.

Results: The acceptance of IUD as a contraceptive was not statistically associated with age \& income of the user. Acceptance for IUD increased with literacy $(P=0.003)$. Almost $77.8 \%$ users were satisfied by the IUD. In total, $66.68 \%$ users, who continued using IUD did not feel any discomfort. The compliance of IUD was significantly associated with the discomfort caused $(\mathrm{P}=0.0008)$ which was found to be most important reason for its removal. The commonest reason for adoption of IUD was a long duration of its use. It was seen that $23.40 \%$ previous contraceptive users and $39.41 \%$ new IUD users accepted it as contraceptive. Its acceptance is especially more in previous IUD users.

Conclusions: Immediate post-partum IUCD has high acceptability and more than $75 \%$ users are satisfied and consider it as a contraceptive option.
\end{abstract}

Keywords: Contraceptive, Immediate post-partum, Cross sectional study

\section{INTRODUCTION}

In the time of population explosion in the developing counties use of contraception is an important factor determining fertility. It is the need of the hour to promote the use of contraceptives. Ideally a contraceptive should be safe and efficacious. It should be based on individual preference and must be user friendly. Intrauterine Contraceptive Device (IUD) is a form of convenient, long acting, rapidly reversible means of contraception. ${ }^{1}$ Their efficacy compares favorably with permanent sterilization. ${ }^{1}$ The intrauterine device is the most widely used reversible methods of contraception in the world today, especially in developing countries where it is used by $14.5 \%$ of women of reproductive age. ${ }^{2}$ The intrauterine device (IUD), chiefly in the shape of the copper IUD, is practiced by more than 150 million women around the globe. ${ }^{3}$ IUDs are extremely effective, safe and relatively inexpensive methods of contraception. With a remarkably low failure rate of less than 1 per 100 women in the first year of employment, the copper T$380 \mathrm{~A}$ is in the top tier of contraceptives in terms of 
efficacy. ${ }^{3}$ It has a longer duration of effectiveness for at least 10 years. ${ }^{4}$ There are many advantages of its use like does not require cooperation of sexual partner. It can be removed at any time with the early return of fertility in the cycle following IUD removal. It can also be introduced after a normal vaginal delivery. ${ }^{5}$

Presently in India only $56.3 \%$ eligible couples are effectively protected against conception by one or another family planning method. ${ }^{6}$ As per National Family Health Survey-3 data for India only $1.7 \%$ females use an IUD as contraceptive. ${ }^{6}$ The latest data available for contraceptive use in India, although indicates wider acceptability of the family planning services compared to the past. ${ }^{7}$ Currently IUD is generally provided in interval period or post puperal and not frequent during immediate postpartum period. Immediate postpartum contraception is the initiation of contraceptive within 48 hours of delivery. ${ }^{8}$ In this study factors affecting IUD as the contraceptive of choice is studied. The study also aims at understanding various social, demographic correlates affecting woman's contraceptive choices. It observes the impact of providing a contraceptive in the immediate postpartum period, free of cost, in a hospital facility under supervision of trained personnel.

\section{METHODS}

In this cross sectional observational study respondents selected, were women who were inserted IUD within 48 hours of normal vaginal delivery during July 2008 to June 2009. The immediate postpartum IUD was inserted in women in Rani Durgavathi hospital Jabalpur (M.P.) India routinely as the policy of the hospital. Due authorization was taken from the ethics committee of NSCB medical college Jabalpur (M.P.) India and superintendent of Rani Durgavathi hospital Jabalpur (M.P.) India to conduct this study. A complete list of all the respondents was obtained from hospital records. A questionnaire was developed for eliciting information about social-demographic characteristics, including education and income levels, number of living children, previous and current contraceptive choices of the women.

A pilot study was performed to test questionnaire to be utilized in the field. During this it was observed that $30 \%$ of women delivering in institute consented for IUD insertion in the postpartum period. The response rate to the questionnaire was found to be $80 \%$. During pilot testing only $70 \%$ respondents were traceable. (Taking the expected population as 8000 , expected frequency as-30\%, at CI-95\%, Confidence limit $5 \%=310+20 \%$ of nonresponders $+30 \%$ of missing respondents) a sample size of 470 (rounding up 465) was obtained. The respondents were selected by using simple random sampling. In total 550 respondents were listed for interview, to compensate for non-respondents and missed respondents. These respondents were traced in field visits with the help of community health worker and interviewed using a questionnaire by trained personnel during January to
March 2010. Informed consent was taken from all respondents prior to participating in the study. Due confidentiality was maintained in data collection and compilation.

The data collected was analyzed using MS excel-2007 and Epi info 7. The associations were found using odds ratio, Chi square test and likelihood ratios.

\section{RESULTS}

It was observed that of 470 respondents, maximum number of respondents i.e. $53.40 \%(251 / 470)$ belonged to $15-24$ years of age, $45.95 \%$ (216/470) belonged to $25-34$ years of age and only $0.63 \%$ (3/470) belonged to age group of 35-44 years. It was observed that continuation of use of IUD was independent of age $(\mathrm{P}=0.38)$ of the user. Also of all 470 respondents taken $52.12 \%$ (245/470) respondents were earning more than $2 \$ /$ day, $47.87 \%$ (225/470) earned less than 2\$/day. However, no association was seen between continuation of use of IUD socioeconomic status (OR-0.751, CI-95\%).

A statistically significant association was seen in continuation of use of IUD and number of living children. It was observed that $36.59 \%(172 / 470)$ users accepted IUD as contraceptive following birth of one child, $14.04 \%(66 / 470)$ used after $2^{\text {nd }}$ childbirth and $8.08 \%$ (38/470) still used IUD after 3 or more live births. (Table-1) It was observed that there was a significant association between continuation of use of IUD and education of respondents (Table 1).

Table 1: Likelihood ratio of factors affecting the continuation of use of contraception.

\begin{tabular}{|llll|}
\hline Factors & $\begin{array}{l}\text { Chi square } \\
\text { value }\end{array}$ & df & P \\
\hline Number of living children & 11.75 & 4 & 0.0193 \\
\hline Education status of respondent & 19.52 & 6 & 0.012 \\
\hline $\begin{array}{l}\text { Duration of first childbirth after } \\
\text { marriage }\end{array}$ & 4.453 & 3 & 0.216 \\
\hline Antenatal visits & 2.890 & 1 & 0.089 \\
\hline Side effects due to IUD & 11.301 & 1 & 0.0008 \\
\hline
\end{tabular}

It was seen that $23.40 \%(110 / 470)$ previous contraceptive users and $39.41 \%$ (184/470) of new IUD users accepted it as contraceptive. A statistically significant association $(\mathrm{P}$ $=0.038$ ) was also seen between compliance of use of IUD inserted in the immediate postpartum period amongst previous IUD users. Nearly $48.18 \%$ (53/110) previous IUD users adopted it again as a means of contraception. It was observed that antenatal visits do not contribute to compliance of use of IUD (Table 1).

In the study it was observed that $62.12 \%(292 / 470)$ users continued using an IUD for a period of $51.98 \pm 16.05$ weeks. Out of 470 users $16.38 \%$ (77/470) users experienced spontaneous expulsion which was confirmed 
by history or by internal exam. It was found that $21.48 \%$ (101/470) user's opted for the deliberate removal of the IUD.

It was also observed that of 292 users who continued using an IUD, 77.8\% (227/292) users were satisfied with IUDs and would like to continue it as contraception in the future as well (OR-5.26, CI-95\%). It was observed that $66.68 \%(195 / 292)$ users who continued using IUD did not feel any discomfort. The side effects due to IUD contributed significantly to the compliance of its usage. (Table 1) Most common discomfort was lower abdominal pain in $36.08 \%(35 / 97)$ users followed by heavy menstrual bleeding in $29.89 \%$ (29/97) users. There was no case reported of uterine perforation, puerperal sepsis or pregnancy with an IUD in place.

The commonest reason for adoption of IUD was a long duration of its use as stated by $29.89 \%$ (61/292) users. Nearly $16.09 \%$ (47/292) found it one time administration user friendly. Of all $15.75 \%(46 / 292)$ adopted it due to its efficacy in preventing unwanted pregnancy. Another reason for adopting it its easy removal stated by $11.98 \%$ $(35 / 292)$ users. It was noted that $10.95 \%(32 / 292)$ adopted it due privacy in use, which was lacking in other available means of contraception. Of all 8.90\% (26/292) used it due to its free of cost availability.

The commonest reason for removal was discomfort due to IUD $34.26 \%(61 / 178)$, planning another pregnancy $21.91 \%$ (39/178), for permanent sterilization $13.48 \%$ $(24 / 178)$ and due to the demise of newborn $11.79 \%$ (21/178). Nearly $10.69 \%$ (19/178) users who opted for voluntary removal of contraception were dissatisfied by IUD and $7.86 \%$ (14/178) did not seek cooperation from spouse to continue it as contraception.

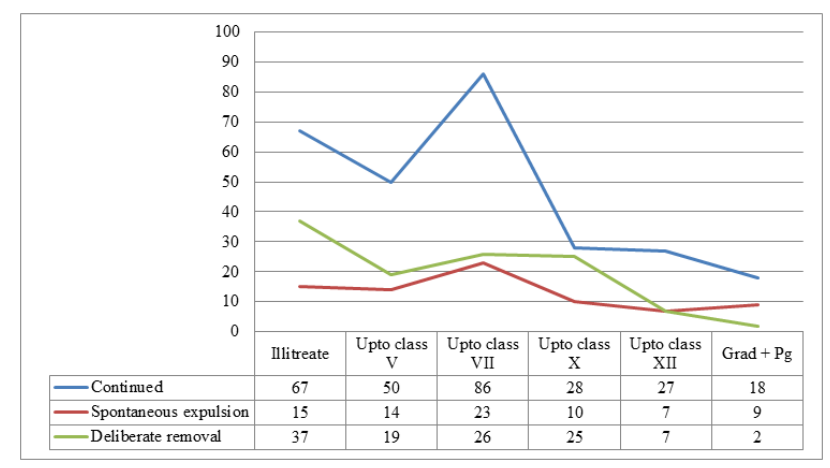

Figure 1: Distribution of respondents on the basis of education status \& compliance with use of IUD.

\section{DISCUSSION}

In the study it was seen that acceptance of IUD is independent of socioeconomic status. But IUD can be used as a means to reduce direct cost expenditure of repeat pregnancy as seen in a study in by Rodreiguz et al. In this study it was concluded that the immediate postpartum IUD reduces direct costs associated with a repeat pregnancy. ${ }^{9}$ Hence a program offering the option of immediate postpartum IUD placement for women would significantly reduce out of pocket expenditures on subsequent pregnancies, particularly in developing countries with considerable population earning $2 \$</$ day.

In the study educated women had greater acceptance and continuation of IUD use. This is consistent with the findings of a study by Sharma and Ratherford in which they have contended that in India, "a 10 per cent increase in the female literacy rate seems to be associated with a 0.5 decline in total fertility rate". ${ }^{10}$

In the study it was discovered that there is a significant association of parity and the role of an IUD as contraception. Al most $22.12 \%$ users continued using IUD after the birth of 2 live issues. This finding is supported by study by Hubacher D that states that parity continues to account for major differences in IUD use. Prevalence of use of IUD in women who wanted future pregnancy were same as those who were not desirous of further childbirths. ${ }^{11}$

The study found that there was a statistically significant association between rates of continuation of use of IUD amongst previous IUD users. As more than $75 \%$ users, who were using IUD previously, continued using it as contraceptive. The findings are similar to that stated by Kaneshiro B, Aeby T, which concluded that cumulative discontinuation rates of the copper T-380A are lower than that have been reported for other methods. Hence indicating that the copper T-380A is highly acceptable to women who had formerly used them as contraceptive. It also states that after 5 years, roughly $50 \%$ of all women, who have a copper T-380A inserted, will continue to use this highly effective contraceptive method. ${ }^{3}$

It is observed that the current status of antenatal services does not contribute to compliance of contraceptive. It can be expected that enhancing the knowledge of women about contraception during regular prenatal visit will increase its acceptability. In the study it was found that the majority of users did not have any discomfort. The adoption of contraception is significantly higher, as it has fewer side effects. Those who had discomfort were mostly lower abdominal pain accompanied by heavy menstrual bleeding. Although it is not associated with life threatening events or uterine perforation. This is similar to as reported by Kaneshiro B, Aeby T, which states that using IUD usage is associated with a low number of adverse events, making it a very safe contraceptive method. Using IUD usage is associated with a low number of adverse events, making it a very safe contraceptive method. ${ }^{3}$

In the study most common reason for discontinuation was due to discomfort by the IUD. This is similar to as stated by Kanishero that the most common reasons for the discontinuation of this method are menstrual bleeding and dysmenorrhea. In the study, $62.2 \%$ users continued using IUD as the contraceptive of choice, this is similar 
to as stated by Kanishero et al. that cumulative discontinuation rates of the copper T-380A are lower than that have been reported for other methods. Hence indicating that the Copper T-380A is highly acceptable to women. ${ }^{3}$

\section{CONCLUSION}

It is concluded that providing immediate post-partum IUCD in the immediate postpartum period has high acceptability and more than $75 \%$ users are satisfied and consider it as a contraceptive option. Its acceptance is especially more in previous IUD users. Compliance to use of IUD was greater in those who did not experience any discomfort due to the IUD. The commonest reason for adoption of IUD was a long duration of its usage as follows by its convenient one time administration, reversibility and ease of removal. The commonest reason for removal was discomfort due to the IUD. It was observed that continuation rates are increased by elevating the level of education of women. Antenatal service should be enhanced as currently it does not create a significant impact on acceptance of contraceptive.

\section{Limitations}

1) During field tracing, all selected cases, users could not be traced.

2) The data collected during interview was based on history of use of contraception by users. The findings could not be confirmed as it was not possible to do internal exam for each respondent.

\section{ACKNOWLEDGMENTS}

We acknowledge to

1) All the faculty members \& residents of department of community medicine NSCB medical college Jablpur M.P.

2) Dr. Neerja Dubey \& personnel at Rani Durgavathi hospital Jabalpur M.P.

3) Dr. P. R. Deo state programme co-ordinator UNFPA Madhya Pradesh India.

Funding: No funding sources Conflict of interest: None declared

Ethical approval: The study was approved by the ethics committee of NSCB medical college Jabalpur (M.P.) India

\section{REFERENCES}

1. Nelson A. Intrauterine contraceptives. Glob Libr Women's Med. 2008;6:Chap-29.

2. d'Arcangues C. Worldwide use of intrauterine devices for contraception. Contraception. 2007 Jun;75(6 Suppl):S2-7.

3. Kaneshiro B, Aeby T. Long-term safety, efficacy, and patient acceptability of the intrauterine Copper T-380A contraceptive device. Int J Women's Health. 2010 Aug;2:211-20.

4. Fortney JA, Feldblum PJ, Raymond EG. Intrauterine devices. The optimal long-term contraceptive method? J Reprod Med. 1999 Mar;44(3):269-74.

5. Grimes DA, Trussell J, Nelson AL. Intrauterine devices (IUDs). In: Hatcher RA, eds. Contraceptive Technology. 19th ed. New York: Ardent Media; 2007: 117-143.

6. International Institute for Population Sciences (IIPS) Mumbai, 2009 for Ministry of Health and Family Welfare (MOHFW), Government of India. Key indicators for India from NFHS-3, India, 2009. Available at: http://www.nfhsindia.org/pdf/India.pdf.

7. Usha Ram. Contraceptive use among young married women in India. In: Usha Ram, eds. International Conference on Family Planning. USA: Bill and Melinda Gates Institute for Population and Reproductive Health; 2009: 1-27.

8. Betty Farrell, Douglas Haber. Module-13: Postpartum and post abortion, contraception. In: Betty Farrell, Douglas Haber, eds. Comprehensive Reproductive Health and Family Planning Training Curriculum. Watertown, MA: Medical Services. Pathfinder Publication; 1998: 1-94.

9. Rodriguez MI, Caughey AB, Edelman A, Darney PD, Foster DG. Cost-benefit analysis of state - and hospital-funded postpartum intrauterine contraception at a university hospital for recent immigrants to the United States. Contraception. 2010 Apr;81(4):304-8.

10. Sharma OP, Retherford RD. IUD use. In: Sharma OP, Retherford RD, eds. Effect of Female Literacy on Fertility in India. Occasional Paper 1. New Delhi: Office of the Registrar General, India, Ministry of Home Affairs, Government of India; 1990: 1-59.

11. David Hubacher, Lawrence B. Finer, Eve Espey. Renewed interest in intrauterine contraception in the United States: evidence and explanation. Contraception. 2011 Apr;83(4):291-4.

DOI: $10.5455 / 2320-1770 . i j r \operatorname{cog} 20141221$

Cite this article as: Trivedi A, Kasar PK, Tiwari

R, Sharma A. Immediate postpartum IUD: analysis of factors making it contraceptive of choice. Int $\mathbf{J}$ Reprod Contracept Obstet Gynecol 2014;3:986-9. 